\title{
MULTICHORD SPECTROSCOPY OF THE DIII-D DIVERTOR REGION
}

by

N.H. BROOKS, A. HOWALD, K. KLEPPER, P. WEST

APRIL 1992

\section{GENERAL ATOMICS}




\section{DISCLAIMER}

This report was prepared as an account of work sponsored by an agency of the United States Government. Neither the United States Government nor any agency thereof, nor any of their employees, makes any warranty, express or implied, or assumes any legal liability or responsibility for the accuracy, completeness, or usefulness of any information, apparatus, product, or process disclosed, or represents that its use would not infringe privately owned rights. Reference herein to any specific commercial product, process, or service by trade name, trademark, manufacturer, or otherwise, does not necessarily constitute or imply its endorsernent, recommendation, or favoring by the United States Government or any agency thereof. The views and opinions of authors expressed herein do not necessarily state or reflect those of the United States Government or any agency thereof. 


\title{
MULTICHORD SPECTROSCOPY OF THE DIII-D DIVERTOR REGION
}

\author{
by \\ N.H. BROOKS, A. HOWALD, K. KLEPPER, P. WEST
}

This is a preprint of a paper to be presented at the 9th Topical Conference on High-Temperature Plasma Diagnostics, March 16-20, 1992, Santa Fe, New Mexico and to be printed in the Proceedings.

\author{
Work supported by \\ Department of Energy \\ Contract DE-AC03-89ER51114
}
GENERAL ATOMICS PROJECT 3466
APRIL 1992

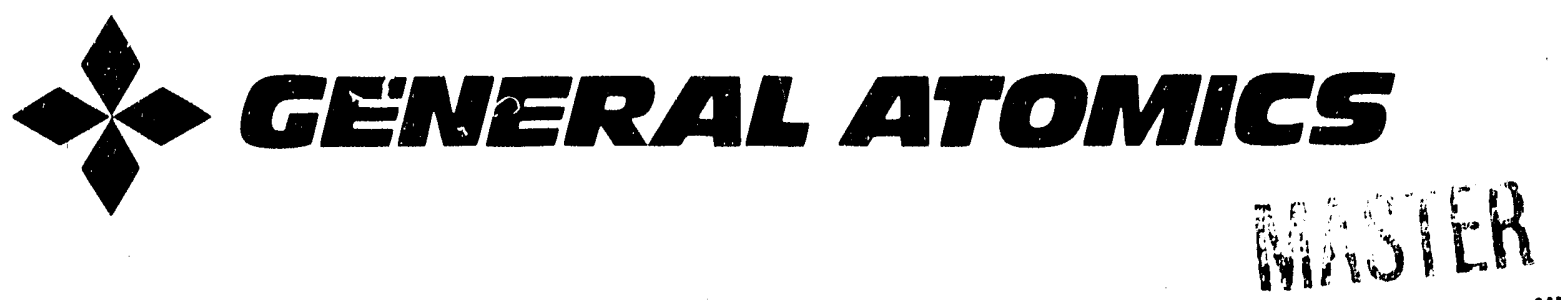




\begin{abstract}
A multichannel spectrometer with high spectral resolution $(0.01 \mathrm{~nm})$ and high temporal resolution $(0.5 \mathrm{msec})$ has been configured to collect data simultaneously from eight viewchords spanning the divertor region of DIII-D. Fiberoptically coupled to a wide-field lens with a vertical view of the vessel floor, the instrument will be capable of differentiating the behavior of impurity line emission at the inner and outer divertor strike points, on and off the Advanced Divertor Program (ADP) ring, on the face of the DIvertor Material Exposure System (DIMES) probe, and in the region of the lower centerpost. Used with a coarse grating (300 grooves/mrn), spectral coverage of each spatial channel is $15 \mathrm{~nm}$ with $0.3 \mathrm{~nm}$ resolution; used in high order with a 1200 groove/mm grating, the instrument is capable of resolving Doppler profiles. Spatial variation of gas recycling and impurity influx will be studied for both singleand double-null divertor configurations in low and high density operating regimes.
\end{abstract}




\section{INTRODUCTION}

Diagnosis of impurity behavior in the divertor region is necessary to validate current models of impurity transport in the divertor, to develop a better understanding of gas-shielded divertor targets and the radiative divertor concept, and to characterize the sputtering behavior of candidate first wall materials under actual divertor conditions expected in a reactor-like device. Visible spectroscopic measurements of low impurity charge states ${ }^{1}$ offers the means to measure the flux of impurities released from the divertor target surfaces; visible measurements of charge transferexcited states in hydrogen-like impurity ions ${ }^{2}$ provides a means to to assess the flux of low- $Z$ impurities travelling in the opposite direction, i.e., transporting out of the core plasma as fully-stripped ions. When coupled with XUV measurements of impurity concentrations in the core plasma, the divertor measurements may be used to establish transport characteristics between the near-surface divertor plasma and the hot plasma inside the closed flux surfaces. Coupled with high time resolution measurements in the divertor, injection of nonintrinsic, nonrecycling impurities offers a means to distinguish the effect of scrape-off-layer (SOL) shielding from that of transport in the core plasma. Prompt detection in the divert or region of low charge states of nonintrinsic impurities can provide a direct measure of the impurity fraction screened by the SOL.

High spectral resolution is important to a determination of impurity fluxes, because the relation between spectral emissivity and flux requires a reasonable knowledge of electron temperature. In the density range $10^{19}-10^{20} \mathrm{~m}^{-3}$ typical of DIII-D's high recycling divertor, thermal equilibrium is achieved between the electrons and the locally generated impurity ions. Therefore, electron temperature may be inferred to good approximation by Doppler profile measurements of the low charge state, impurity ions.

\section{SPECTROMETER DESCRIPTION}

A multichannel spectrometer system with both high spectral resolution $(0.01 \mathrm{~nm})$ and high temporal resolution $(0.5 \mathrm{msec})$ has been built to collect data simultaneously from eight viewchords. The instrument is coupled through a CAMAC interface to a remotely located MicroVAX computer for data acquisition, control, and analysis. 
Spectra from 512 time slices are collected with 12-bit resolution from each tokamak pulse.

The base instrument for the multichord system is a $1.33 \mathrm{~m}$ Czerny-Turner spectrometer manufactured by $\mathrm{McPherson}$ Corporation. Its combination of stigmatic imaging and high spectral resolution ${ }^{3}$ is an essential feature of the design. Light from multiple viewchords through the DIII-D divertor will be conveyed to the spectrometer by means of $45 \mathrm{~m}$ long, monofilamentary quartz fibers with $0.6 \mathrm{~mm}$ core diameter. Initially, those fibers will be proximity coupled to the spectrometer (in groups of eight) by butting their output tips against the entrance slit; in the future, $\mathrm{f} /$ number matching between fiber and spectrometer will be improved by imaging the fiber tips with a magnification of 2.5 onto a fiberoptic transformer that mates to the entrance slit.

The eight discrete inputs give rise to eight spectral bands lying one above another in the spectrometer focal plane. A microchannel plate, image intensifier with quartz input window and S-20 photocathode acts both as light amplifier and wavelength converter for the near ultraviolet, without distorting the two-dimensional (2-D) geometric pattern of dispersed light in the focal plane. The output from the intensifier's P-20 phosphor is well-matched in color distribution to the spectral response of the Reticon ${ }^{\mathrm{TM}}$ linear photodiode array in the two Fast Optical Multichannel Analyzer (FOMA) cameras. ${ }^{4}$ The FOMA cameras were built at General Atomics for use on DIII-D. An image transformer containing eight rigid glass conduits maps the 2-D output pattern of the intensifier onto the 1-D detectors in the FOMA cameras as shown in Fig. 1. The $6 \mu$ fibers in the rigid conduits provide excellent resolution and coherency, and the small distance between input and output tips contributes to easy support of the camera assembly off the faceplate of the spectrometer. Because of the fragility of the glass transformer at low tempex ature, the FOMA cameras are cooled with gas at room temperature.

The spectral resolution of the complete spectrometer system has been measured with a low pressure mercury lamp. With a 1200 groove $/ \mathrm{mm}$ grating used in fourth order, a spectral resolution of $0.12 \AA$ is observed for the $\mathrm{Hg} 313.1$ doublet. 


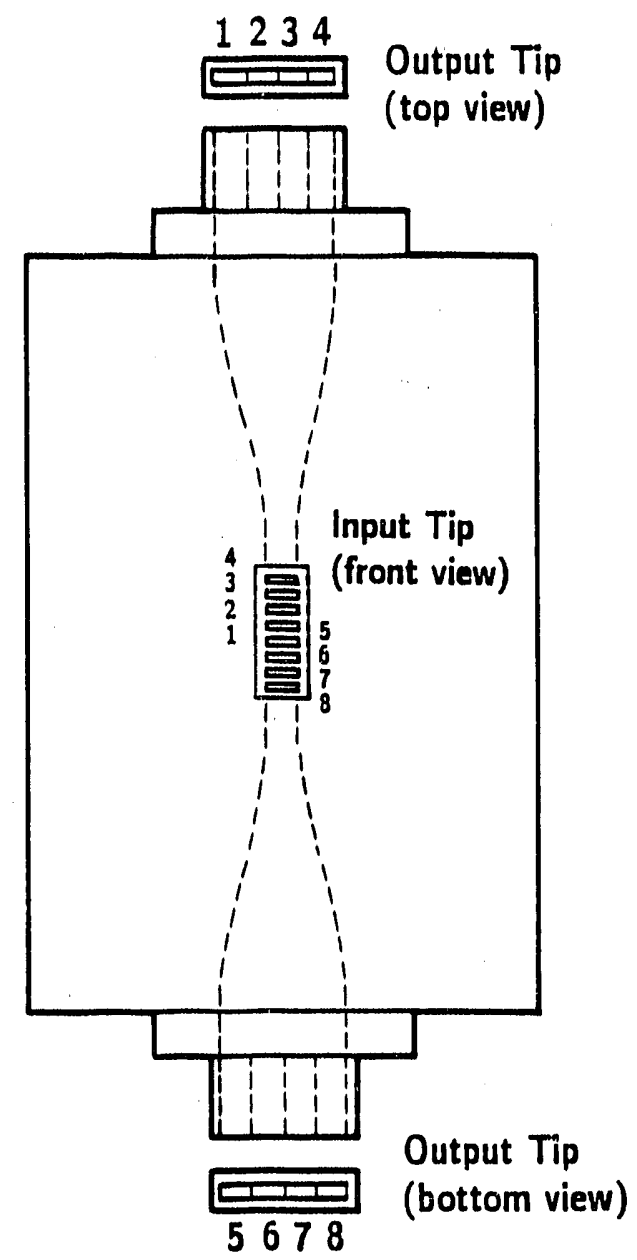

Fig. 1. A geometric image transformer maps the 2-D pattern of eight spectra onto the 1-D Reticon detectors in the FOMA cameras.

\section{VIEWING GEOMETRY IN DIII-D}

The viewing geometry in DIII-D of the multichordal spectrometer system is shown in Fig. 2. The fan of viewchords in the poloidal plane is overlaid by the MHD flux contours of a single-null divertor configuration for reference. Fifteen fibers will be arranged in a crossed pattern in the image plane of a wide-angle, $f / 4$ lens: one line of fibers oriented in the radial direction, the other in the toroidal direction. With a magnification of 35 on the floor of the vessel, each $0.6 \mathrm{~mm}$ diameter fiber will collect light from a circle $20 \mathrm{~mm}$ in diameter. As shown in Fig. 2(b), the fiber views are carefully located away from the edges of tiles, where gaps or steps in height might 

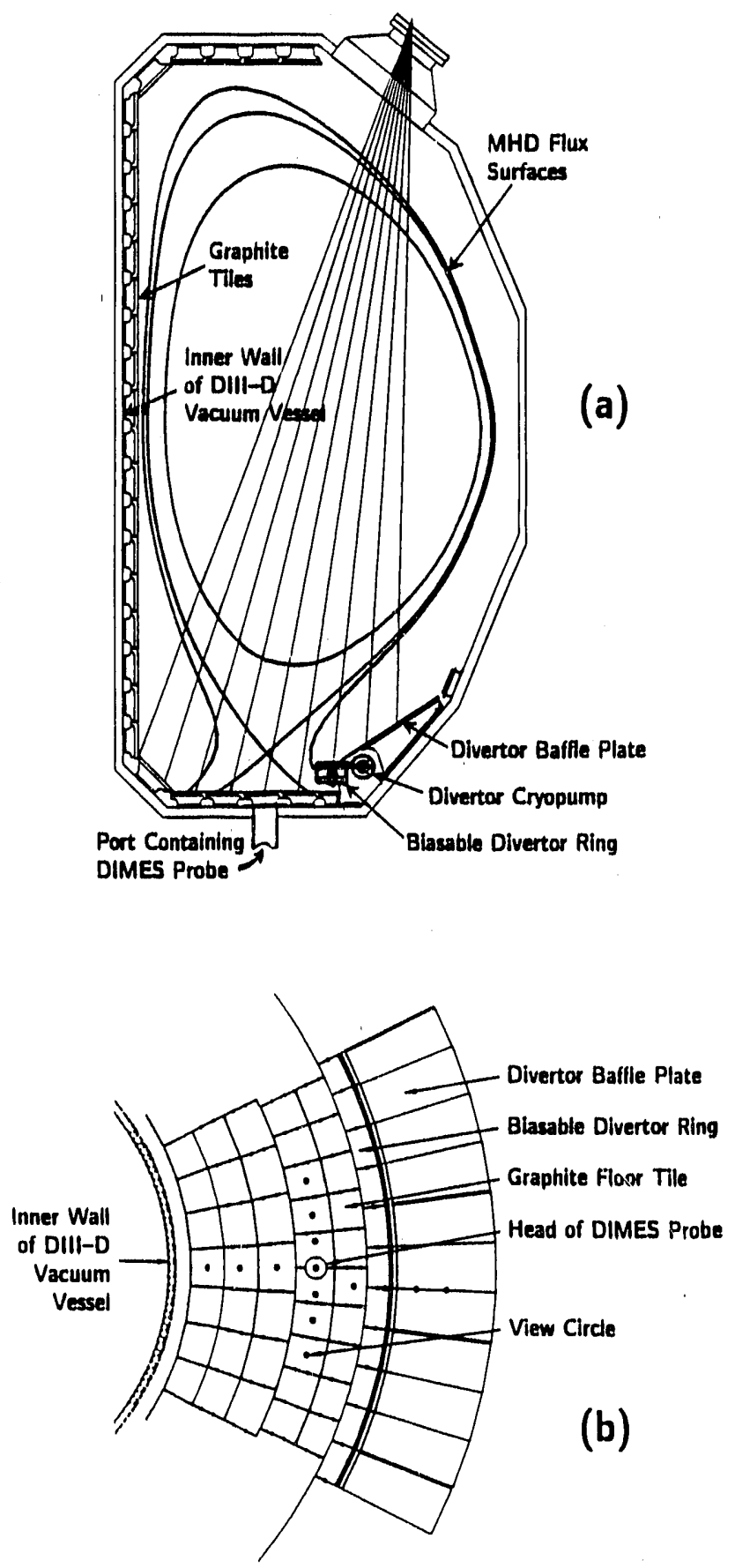

Fig. 2. (a) The fan of viewchords in the poloidal plane spans the interaction region with the vessel floor of the single-null divertor configuration. (b) The solid black circles show the locations of the fifteen fiberoptic views on the concentric rings of graphite floor tiles; the central circle in the crossed pattern intersects the head of the DIMES probe. 
produce local departures from the average recycling intensity. The central chord of the crossed pattern is aimed at the face of the DIMES sample. The performance characteristics of different first-wall candidate materials will be tested on the head of this probe mechanism.

To maximize signal, the size of the view circles on the floor has been chosen comparable with the width of the peaks in the heat deposition pattern observed during $\mathrm{H}$-mode with infrared cameras. By repetitively scanning the $\mathrm{X}$-point position over a distance equal to the separation between view circles on the divertor floor, the complete spatial profile of the impurity radiation in the divertor may be obtained for the entire period of each tokamak discharge. A map with such high spatial resolution is necessary to compare impurity influx at inner and outer strike points, on the ADP ring, and on the DIMES probe.

\section{SAMPLE DATA FROM A SINGLE VIEWCHORD}

Preliminary data on divertor impurity behavior has been obtained with a single viewchord aimed at the outer strike point of a single-null divertor configuration. Relative sizes of the hydrogen and carbon recycling fluxes may be qualitatively inferred from the relative intensities in Fig. 3 of $D_{\alpha} 656.1$ and the CII 658.0 doublet. Representative spectra are shown for similar tokamak discharges under three different scenarios of vessel wall conditioning: inter-shot helium glow conditioning only, carbonization plus inter-shot glow, and boronization plus inter-shot glow. As seen previously on TEXTOR and other devices, ${ }^{5}$ carborization leads to a measurable reduction in the carbon impurity flux and boronization leads to its nearly complete elimination, at least transiently. Carbon took more than ten shots following a fresh boronization to reappear above the background noise. When the multichord system becomes operational, we will be able to compare the erosion rate of the protective boron film at the inner and outer strike points.

With the single viewchord aimed through the $\mathrm{X}$-point of the single-null configuration, the CIII 464.7 triplet has been monitored during divertor gas puffing experiments aimed at reducing the heat fiux to the divertor tiles. Pronounced increases in the CIII line radiation from the divertor waist are seen during strong gas puffing; this enhanced impurity radiation is correlated with an increase in the bolometer signal from the same region and a strong reduction in heat flux to the 


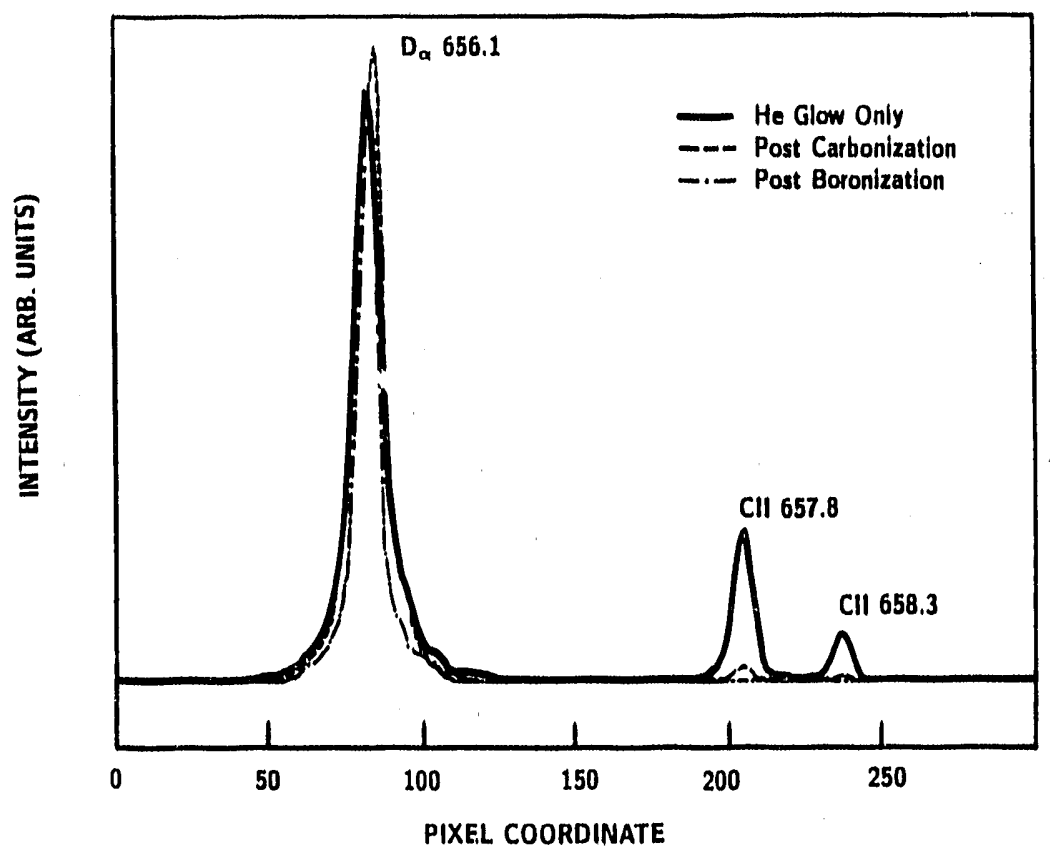

Fig. 3. The relative intensity of $\mathrm{D}_{\alpha}$ and the $\mathrm{Cll}$ doublet at the outer divertor strike ring for (a) inter-shot helium glow wall conditioning, (b) carbonization and inter-shot glow, and (c) boronization and inter-shot glow.

divertor tiles. Ion temperature calculated from the doppler profile of the CIII line show a temperature consistent with emission from a region at or above the $\mathrm{X}$-point itself.

\section{ACKNOWLEDGEMENTS}

This work was supported by the U.S. Department of Energy under Contract No. DE-AC03-89ER51114.

\section{REFERENCES}

1 K. Behringer, et al., Plasma Phys. Controlled Fusion 31, 2059 (1989).

2 R.C. Isler, Physica Scripta 35, 650 (1987).

3 M. Czerny, A.F. Turner, Z. Physik 61, 792 (1930). 
4 J.S. Haskovec, etal., Fusion Engineering (Proc. 13th Symp. Oak Ridge, 1989) 1,153 (1990).

5 J. Winter et al., J. Nucl. Mater. 162-164, 713 (1989). 

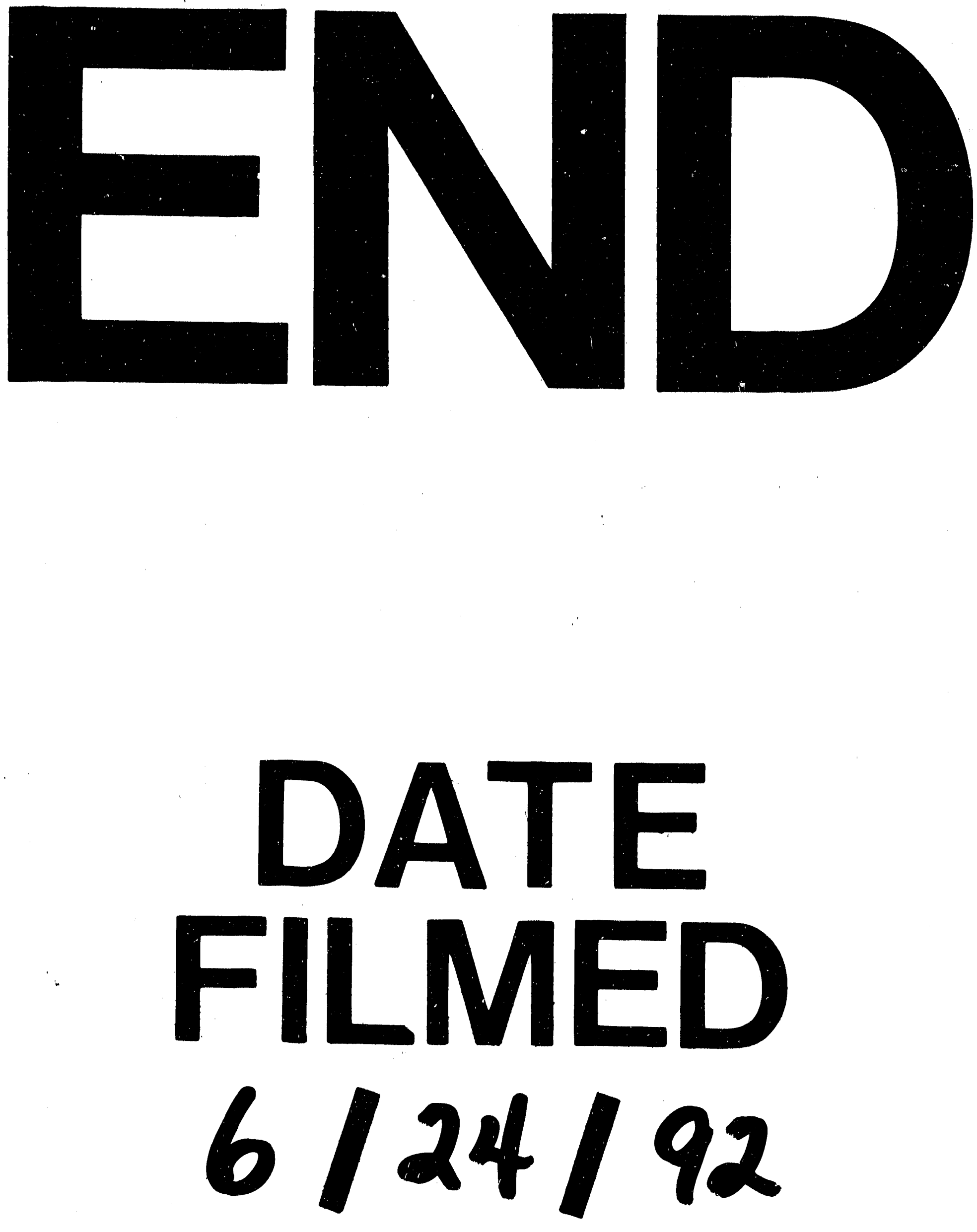

$6 / 24 / 92$

1 